\title{
Use of the program and goal-oriented approach to observe the vertical displacements of the earth's surface in Russia
}

\author{
Victor Volkov ${ }^{1}$, and Nikita Volkov, ${ }^{1, *}$ \\ ${ }^{1}$ Saint Petersburg State University of Architecture and Civil Engineering, Vtoraya Krasnoarmeiskaya \\ str., 4., 190005, St. Petersburg, Russia
}

\begin{abstract}
The paper considers the problematic issues of the special aspects of solution of the problems of modern geodynamics and technogenic geomechanics in oil and gas fields based on the results of relevelling. The disadvantages and fundamental errors traditionally made by mining and land surveyors in organizing and performing re-levelling on the territories of oil and gas fields are given. The results of high precision levelling, obtained on the territory of an oil and gas field using the program and goal-oriented approach for its formulation, are presented. The representativeness and sufficient accuracy of obtaining the results of relevelling allowed us to establish significant speeds of geodynamic and technogenic displacements of the earth's surface $(0.4-3.6 \mathrm{~mm} / \mathrm{year})$ in the shortest time possible with high economic efficiency.
\end{abstract}

\section{Introduction}

The general tasks of repeated geodetic observations performed on the territory of oil and gas fields in specially created technogenic geodynamic polygons include identifying the presence and determining the degree of development of geodynamic processes in stressstrain zones of tectonic disturbances [1-3].

The uniqueness of repeated geodetic observations lies in the fact that their results are used for both practical and research purposes implemented when solving the fundamental problem of modern movements of the earth's crust [1,4-8]. At the same time, geodesic observations, the main method of which is re-levelling, require prompt receipt of development rates of modern geodynamics, as well as deformations of reservoirs and mountain ranges lying over the deposit, eliminating the impact of natural factors on the levelling results [1,9]. At the present stage, the formulation of repeated geodetic observations at geodynamic survey loops is carried out according to the program of precise re-levelling of $1^{\text {st }}$ and $2^{\text {nd }}$ classes. Levelling is carried out along lines with a length of 20 $100 \mathrm{~km}$, crossing along and across the strike of mining allotments of reservoirs and deposits of hydrocarbons that are attached to the initial levelling points located beyond the boundary of deposits at a distance of more than $5 \mathrm{~km}[1,3]$.

\footnotetext{
*Corresponding author: volkov.nikita@yahoo.com
} 


\section{Methods}

With the existing traditional approach to re-levelling at technogenic geodynamic test sites, errors in determining the speeds of tectonic movements $\mathrm{V}$ and technogenic movements of the earth's surface in most cases significantly exceed the values of the established speeds, which is convincingly confirmed by the estimated inequality:

$$
m_{V} \leq \frac{M_{k m}}{T} \sqrt{2 L},
$$

where $M_{k m}$ - the mean square error of precise levelling per $1 \mathrm{~km}$ of stroke for $1^{\text {st }}$ and $2^{\text {nd }}$ classes of levelling 0.8 and $2 \mathrm{~mm}$ (according to Russian regulatory requirements), respectively; $\mathrm{T}$ (year) - frequency of re-levelling of profile lines of length $\mathrm{L}, \mathrm{km}$.

It follows from the expression (1) that re-levelling (frequency - 1 year) lines of $40 \mathrm{~km}$ (leveling $1^{\text {st }}$ class) and $20 \mathrm{~km}$ long (leveling $2^{\text {nd }}$ class), installed for technogenic (local) geodynamic test sites by Russian regulatory requirements, with usage programs of $1^{\text {st }}$ and $2^{\text {nd }}$ classes levelling, the errors in determining the speeds of technogenic vertical displacements of the earth's surface and the manifestations of modern geodynamics within the geodynamic test sites are 7 and $12 \mathrm{~mm} /$ year, respectively. When reducing the frequency of re-levelling to once every six months, errors $m_{V}$ increase dramatically and amount to 14 and $25 \mathrm{~mm} /$ year, respectively, for precise levelling of $1^{\text {st }}$ and $2^{\text {nd }}$ classes, which is unacceptable from the standpoint of the general requirements to monitoring technogenic deformation processes in the territories of exploited oil and gas fields [1-3]. Consequently, the traditional approach to the formulation of re-levelling and interpretation of its results at geodynamic test sites, which is not taking into account the specifics of surveying tasks solved on the basis of the results of re-levelling, is subject to radical changes.

When creating observation systems, the principle of "reasonable sufficiency" [1] was observed with regard to the volume, content, and accuracy of instrumental observations, the results of which, according to informativeness, accuracy, and representativeness, should promptly ensure control over the normal technological cycle of work and prediction of adverse environmental situations at the Yamburg OGCF (oil-gas condensate field), which is located in Russia and covers an area of 8,200 square kilometers. Taking into account the prevailing natural and technogenic conditions on a large area of the Yamburg OGCF, within the framework of geodynamic test sites, a network of repeated geodetic observations has been created to solve geodynamic and geomechanical tasks, including 21 observation systems, four geodynamic profiles, and four basic satellite stations.

Observation systems designed to control the movement of the earth's surface and technogenic deformations of reservoirs, caused by the extraction of hydrocarbons from the depths, have two modifications. Each of the observation systems consists of reference (initial) and control (deformation) levelling points. In contrast to the traditional approach, at the geodynamic test site of the Yamburg OGCF, the placement of the reference levelling points (RLP) outside the gas production contour is performed vertically under conditions that exclude the influence of the processes related to the studied factor - development of gas deposits - on in their stability. As such reference points, exploratory wells equipped with a levelling mark (benchmark) are used, which are converted to category of conserved and referred to as reference wells. The depth of their laying exceeds the depth of the reservoir layers being worked out. To establish the quantitative characteristics of the vertical component of technogenic displacements of the earth's surface, 17 control sites were created at the geodynamic test site, formed by a reference well (reference levelling point) and two tubular ground levelling points (GLP) of Type 150 (in Russian classification) located at a distance of no more than $100 \mathrm{~m}$ from it [1-3]. The Type 150 tubular ground 
levelling points recommended by Russian regulatory requirements for areas with permafrost in order to eliminate the effects of frost heaving on them are laid to a depth $z$ according to the recommendations given in:

$$
z=h\left(1+1,4 \frac{T_{s h}}{T_{f r}}\right),
$$

where $h$ - the depth of seasonal thawing (freezing) of soils, which is calculated for a specific climatic zone; $T_{s h}$ and $T_{f r}$ - respectively, the specific forces of frost heaving and freezing of the reference tube of the leveling point with permafrost soil, the values of which for a specific type of permafrost soil.

To determine the quantitative characteristics of the reservoir deformations, observation systems were equipped in the form of profile lines - class $1^{\text {st }}$ precise re-levelling lines divided into sections every $0.3-0.5 \mathrm{~km}$. To establish the kinematic characteristics of the modern geodynamics of the subsoil and the manifestations of anomalous geodynamics associated with the development of the subsoil, four geodynamic profiles were laid at the Yamburg geodynamic site. Geodynamic profiles (GP-1, 2, 3, 4) are represented by four relevelling lines of $1^{\text {st }}$ class, divided into sections of $0.5-1 \mathrm{~km}$ long. They intersect the zones of the sub-latitudinal fault of the Aneryakhinskaya area, the supposed sub-latitudinal northern fault, the submeridianal fault along the developed Cenomanian deposit, and the tectonic faults of the northeast and submeridianal strike. The re-levelling lines of geodynamic profiles are fixed with Type 150 ground levelling points, which are paired with reference wells at the end points.

It is known that to determine the velocities of the vertical displacements of the earth's surface and the speeds of deformation processes according to the results of re-levelling, the levelling accuracy in cycles, according to expression (1), should be assigned in accordance with inequality:

$$
M_{\text {км }} \leq \frac{\lim m_{V} T}{\sqrt{2 L}}=\frac{V_{p r e d} T}{4 \sqrt{2 L}},
$$

where $\lim _{V}$ - limit value of the error in determining the speed of the earth's surface displacement with its predicted value $V_{\text {pred }}$.

From inequality (3), it follows that the length $\mathrm{L}$ of the re-levelling lines at the geodynamic test site should be assigned in accordance with the predicted values of the determined speeds $V_{\text {pred }}$ established by the re-levelling frequency $T$ and its accuracy according to the analytical expression:

$$
L \leq \frac{1}{2} \frac{V_{\mathrm{lim}}^{2} T^{2}}{16 M_{k m}^{2}}=\frac{V_{\mathrm{lim}}^{2} T^{2}}{32 M_{k m}^{2}},
$$

where $V_{\text {pred }}$ - predicted values of vertical speeds of the earth's surface, established on the basis of analytical and numerical models for calculating subsidence of the earth's surface, as well as according to the geodynamic zoning of the territory in the process of developing a mining and geological substantiation of the creation of a geodynamic test site, developed by mining surveyors and geophysicists.

When setting the frequency of re-levelling of $1^{\text {st }}$ class, performed at the Yamburg geodynamic test site, the requirements for the significance of the determined speeds $V$, manifestations of technogenic, geomechanical and geodynamic processes were used as a base. From expression (4), an inequality is obtained that governs the acquisition of 
significant speeds $V_{\text {sig }}$ (confidence probability $\beta=0.955$ ) based on the results of relevelling, taking into account the lengths of re-levelling lines, its accuracy and frequency. It has the following form:

$$
V_{\text {sig }} \geq \frac{M_{k m}}{T} \sqrt{32 L}
$$

From inequality (5), it follows that on profile lines and geodynamic profiles with established lengths of levelling lines $L=\sum S_{i}$ ( $S_{i}$ are the lengths of levelling line sections) and a certain levelling class $\left(1^{\text {st }}-4^{\text {th }}\right.$ in Russia), the significance of the obtained speeds of the vertical movements of the earth's crust are also regulated by the frequency $T$ of repeated levelling. The table shows the predicted significant (confidence probability $\beta=$ 0.955) values of the speeds of manifestations of modern geodynamics, vertical displacements of the earth's surface, and deformations of the reservoir layers, which are determined by the results of precise re-levelling of $1^{\text {st }}$ class $\left(M_{k m}=0.8 \mathrm{~mm} / \mathrm{km}\right)$ of the Yamburg test sites at one and two years intervals.

Table 1. Predicted (numerator) and obtained in cycles of repeated levelling (denominator) values of significant velocities (mm/year) with different length of levelling lines ( $\mathrm{km}$, italic).

\begin{tabular}{|l|l|l|l|l|l|l|l|}
\hline \multirow{2}{*}{ Frequency } & \multirow{2}{*}{$\begin{array}{l}\text { Control } \\
\text { sites }\end{array}$} & \multicolumn{4}{|l|}{ Profile lines } & \multicolumn{4}{l|}{ Geodynamic profiles } \\
\cline { 2 - 8 } & 1 & 1,4 & 2,4 & 2,5 & 5,8 & 6,4 & 6,8 \\
\hline 1 year & $\frac{0,6}{0,6}$ & $\frac{5,4}{1,2}$ & $\frac{7,1}{1,6}$ & $\frac{7,3}{5,0}$ & $\frac{11,1}{7,7}$ & $\frac{11,6}{8,1}$ & $\frac{12,0}{8,3}$ \\
\hline 2 years & $\frac{0,3}{0,3}$ & $\frac{2,7}{0,6}$ & $\frac{3,5}{0,8}$ & $\frac{3,6}{2,5}$ & $\frac{5,5}{3,8}$ & $\frac{5,8}{4,0}$ & $\frac{6,0}{4,2}$ \\
\hline
\end{tabular}

At the Yamburg geodynamic test site, special attention is paid to the stability of all levelling points to the effects of natural exogenous factors, which is provided within $\delta H_{a l} \leq m_{s t} \sqrt{2 n}$ (where $m_{s t}$ is the levelling error at the station; $n$ is the number of stations in the levelling course) at the control sites and $\delta H_{a l} \leq M_{k m} \sqrt{2 L}$ on the lines of re-levelling of profile lines and geodynamic profiles. The stability of levelling points $\delta H_{a l}$ to the effects of natural exogenous processes is achieved by a scientifically based approach to the calculation of structural elements and depths of laying leveling points, which takes into account the prevailing climatic, engineering and geological conditions for laying lines of high precision re-levelling, as well as the effect of the geothermal field on the deformation of levelling points.

\section{Results}

In the autumn and winter period of 2015-2017, in the observation systems of the Yamburg geodynamic test site, precise re-levelling of $1^{\text {st }}$ class was performed at a frequency of $T=1$ year. The assessment of the quality of levelling in each cycle is made on the basis of the calculated differences in elevations $d_{1}, d_{2}, d_{3}, d_{4}, d_{5}, d_{6}$ according to the formulas which are using in Russian regulatory requirements. At the same time, for a profile lines and geodynamic profiles, accumulations of differences $d_{1}, d_{2}, d_{5}$ were established that do not 
exceed the value of $0.04 \mathrm{~mm} / \mathrm{km}$, and accumulation of differences $d_{3}, d_{4}, d_{6}$ was no more than $0.08 \mathrm{~mm} / \mathrm{km}$, which indicates the absence of heaving of spikes in the process of levelling. The values of the mean square error of levelling per $1 \mathrm{~km}$ of stroke in the observation cycles did not exceed the following values: at the control areas $m_{s t} \leq 0.1 \mathrm{~mm}$; on profile lines $M_{k m} \leq 0.18 \mathrm{~mm} / \mathrm{km}$; on geodynamic profiles $M_{k m} \leq 0.55 \mathrm{~mm} / \mathrm{km}$.

In accordance with the obtained accuracy characteristics of the re-levelling for the Yamburg geodynamic test site, the minimum values of the significant values of the speeds of the vertical earth's surface displacements (see the table), reliably established by the results of the re-levelling performed at intervals of 1 and 2 years according to the program of $1^{\text {st }}$ class, were obtained. After rejection of insignificant values of the earth's surface displacement speeds, obtained from the results of $1^{\text {st }}$ class precise re-levelling performed at intervals of 1 and 2 years at control sites and profile lines of the Yamburg geodynamic test site, a diagram of the earth's surface vertical displacements was made (Fig.1).

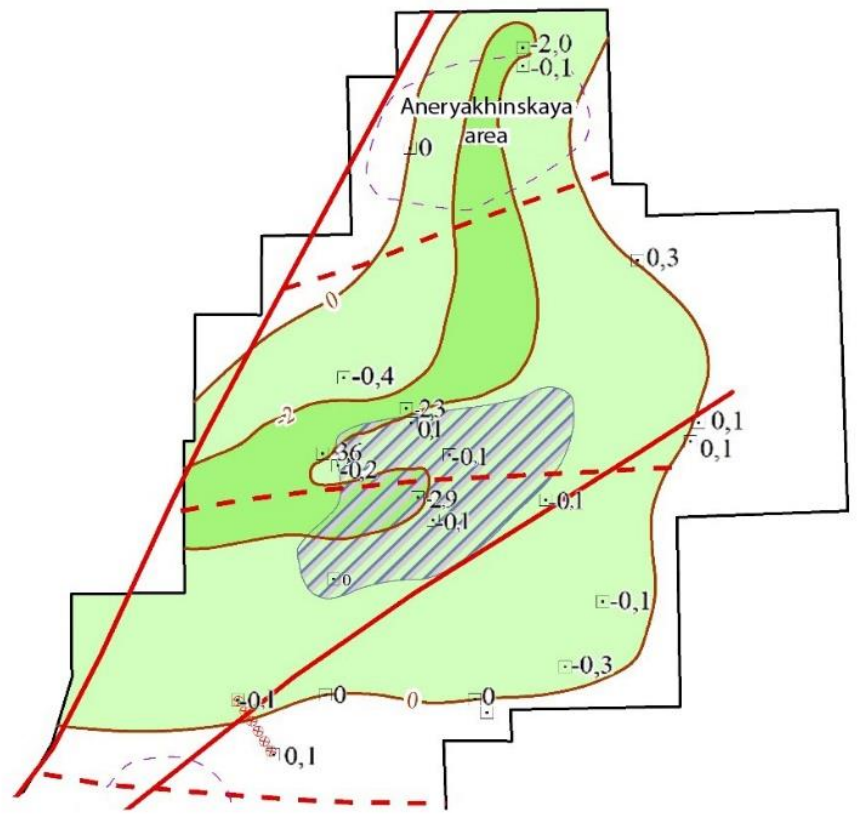

\section{Legend}

$\square 0,1$ Control site and values of the speeds of the vertical earth's surface displacements

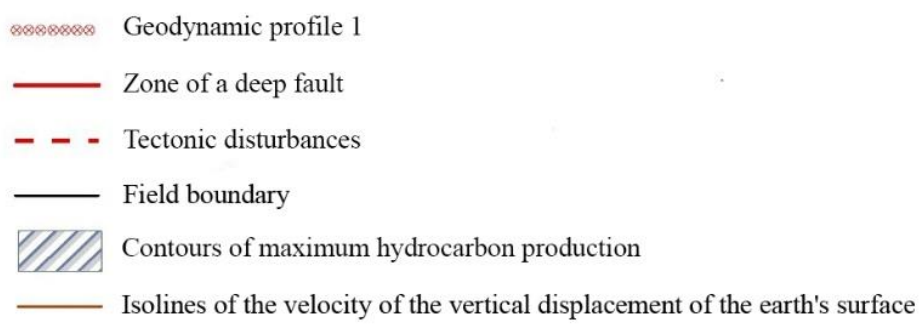

The area of the velocity of the vertical displacement of the earth's surface:

from 0 to $-2 \mathrm{~mm} /$ year

from -2 to $-4 \mathrm{~mm} /$ year

Fig. 1. Scheme of speeds of vertical movements of the earth's surface at the Yamburg GP for the period 2015-2017. 
The diagram shows that the areas of significant displacements (subsidence) of the earth's surface, characterized by speeds of $V_{\Delta H}$ from -0.4 to $-3.6 \mathrm{~mm} / \mathrm{year}$, are confined to the contours of the developed Lower Cretaceous deposits and Aneryakhinskaya area. Based on the results of re-levelling performed in the second and third cycles, only one of the four geodynamic profiles showed significant negative vertical displacement speeds $V_{\Delta H}$ (Fig. 2) of control levelling points located in the zone of a deep fault.

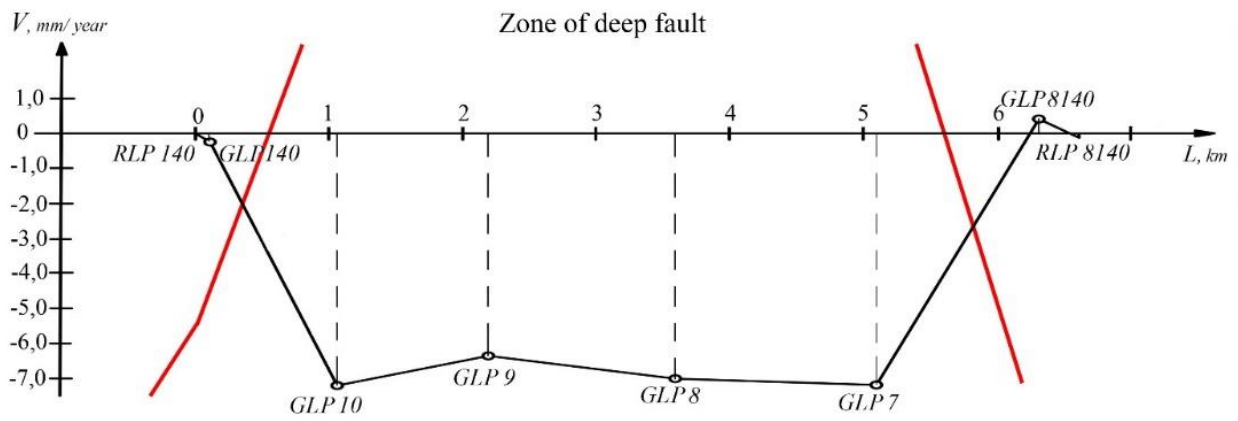

-0 The velocities of the vertical displacements of the earth's surface on GP 1 during 2016-2017

Fig. 2. The graph of vertical displacement velocities of level points of GP for the period 2015-2017 (cycles 1-3).

It was found that the control levelling points located in the zone of a deep fault are shifted with speeds $V_{\text {sig }}>6 \mathrm{~mm} /$ year relative to the levelling points located on the sides of the fault and maintaining stability within $\delta H \leq 4 \mathrm{~mm}$ during 2015-2017. The reasons for the manifestation and interrelation of such displacements with natural geodynamic and technogenic geomechanical processes are the subject of further comprehensive studies at the Yamburg geodynamic test site [4, 10].

\section{Conclusions}

Based on surveying and geodetic surveys performed at the Yamburg geodynamic test site, we can draw the following conclusions:

1. The proposed program and goal-oriented approach to surveying and geodetic monitoring of geodynamic and geomechanical processes in areas of development of oil and gas fields is fundamentally different from the traditional approach by reliability, monitoring efficiency and representativeness, and, consequently, high efficiency of the results;

2. Achieving the necessary accuracy of re-levelling, as well as obtaining reliable and representative results of levelling at the geodynamic test sites of oil and gas fields is a complex scientific and practical task, the successful solution of which at the present stage is possible by building special observation systems within the geodynamic test site;

3. Separate observation systems of geodynamic test sites of oil and gas fields make it possible to effectively solve geodynamic problems while observing the principles of "reasonable sufficiency" with regard to the quality of observation results and material costs for their obtaining.

\section{References}

1. V. Volkov, V. Smirnov, Applied Mechanics and Materials 725-726, 118-123 (2015) 
2. Y.O. Kuzmin, V.A. Churikov, Geophysical Journal International 133, 607-614 (1998)

3. A. Panzhin, Proceedings of the 1st International conference of rock dynamics and applications, ROCDYN-1 1, 319-324 (2013)

4. M. Haoa, Q. Wang, Z. Shen, D. Cui, L. Ji, Y. Li, S. Qin, Tibetan Plateau Tectonophysics 632, 281-292 (2014)

5. A. Richter, E. Ivins, H. Langea, L. Mendoza, L. Schröder, J.L. Hormaeche, G. Casassa, E. Marderwald, M. Fritsche, R. Perdomo, M. Horwath, R. Dietrich, Earth and Planetary Science Letters 452, 206-215 (2016)

6. M. Amighpey, B. Voosoghi, S. Arabi, Tibetan Plateau Tectonophysics 679, 169-179 (2016)

7. S. Qin, W. Wang, Sh. Song, Geodesy and Geodynamics 9(2), 115-120 (2018)

8. T. Zhang, W.B. Shen, Y. Pan, W. Luan, GRACE observations Advances in Space Research 61(4), 1005-1016 (2018)

9. J. Mäkinen, H. Koivula, M. Poutanen, V. Saaranen, Journal of Geodynamics 35(4-5), 443-456 (2003)

10. T. Kall, T. Oja, K. Tänavsuu, Tibetan Plateau Tectonophysics 610, 25-38 (2014) 